\title{
Fabrication of Low Cost Composite Spargers and Their Performance in Polar and Non-Polar Liquids
}

\author{
Behnam Mostajeran Goortani, Elham Khoshandam \\ Department of Nano Sciences and Technologies Engineering and Renewable Energy Engineering Department \\ Faculty of Advanced Sciences and Technologies, University of Isfahan \\ Isfahan, Iran \\ b.mostajeran@ast.ui.ac.ir
}

\begin{abstract}
Spargers are porous devices used for the continuous injection of gas bubbles into liquids. They have many applications like effective aeration in bio reactors, enhanced oil recovery, flotation, filtration and water treatment. In this study low cost spargers are fabricated, utilizing a new method. The bubble sizes and distributions are determined in an experimental setup comprising a bubble column equipped with a semi-professional camera to record the sizes of the bubbles in the column and resulting bubbles are photographed at different gas flow rates. First substrate of glass-bead spargers are fabricated. They are then covered by a layer of copper. The effect of reaction temperature and fluid properties are investigated on the size and the distribution of the produced bubbles. The results showed that the pore size of flat composite sample is decreased to $100 \mathrm{~nm}$ by coating by plasma focus deposition device; consequently, all bubbles produced by this sample are less than $0.1 \mathrm{~mm}$ inside kerosene. Comparison of BSD for all samples indicated that the smallest bubbles are produced in kerosene. By controlling the sintering conditions and through our innovative reaction and sintering method, we fabricated flat and conical composite spargers that produce $100 \%$ bubbles of less than $0.1 \mathrm{~mm}$ diameter, and in kerosene a foamy bubble column is formed.
\end{abstract}

Keywords: Sparger, Bubble size distribution, Gas flow rate, Sintering, Non-polar liquid

\section{Introduction}

Sintering is a typical method to fabricating porous pieces and is a method in powder metallurgy. Pressed powder is heated to form a solid piece of desired shape [1]. Basic mechanisms of sintering are: solid state sintering, sintering in presence of a passing liquid phase, and activated sintering [2]. In solid state sintering, liquid phase and atoms of solid particles are interacting to form a porous lattice. Sintering in presence of a passing liquid phase occurs when a mix of two different metal powders exist, the powder of lower melting point melts. The liquid phase is diffused between particles and connects particles together to form a porous lattice. A particular type of sintering with a passing liquid phase is activated sintering, where, small amount of metal or metal composition is added to result diffusion of metal atoms [2, 3].

One of the applications of porous devices is in spargers [4]. The injected gas in the sparger detaches and form bubbles on the surface. The forces in acting on a bubble consist of buoyancy $\left(F_{b}\right)$, gas momentum $\left(F_{g}\right)$, pressure $\left(F_{p}\right)$, drag $\left(F_{d}\right)$, inertial $\left(F_{i}\right)$ and surface tension $\left(F_{\sigma}\right)[5]$ :

At bubble separation point, upward and downward forces are equal:

$$
\mathrm{F}_{\mathrm{b}}+\mathrm{F}_{\mathrm{g}}+\mathrm{F}_{\mathrm{p}}=\mathrm{F}_{\mathrm{d}}+\mathrm{F}_{\mathrm{i}}+F_{\sigma}
$$

In the previous work of the authors [6] disc spargers of desired bubble size distribution through a new method are fabricated. In this work non-polar liquids are of concern and higher ranges of gas flow rate are reached. To follow the same context, the objective of this study is increasing the surface area of sparger in order to decrease pressure drop and to coat the samples surface by a layer of copper and then oxidize the surface in order to increase wettability and improve their application in non-polar liquids. 


\section{Methods and Materials}

\subsection{Materials and Tools}

Glass bead powder (purchased from PANA INC, Tehran, Iran) is utilised. Composition of the powder is tabulated in Table 1. Two types of copper powder are utilized with purity of $99.9 \%$. One with particles size of less than $149 \mu \mathrm{m}$ (purchased from Atlantic Equipment Engineers) and the other with particle size less than $20 \mu \mathrm{m}$ (MERK).

Table 1: Chemical composition of glass raw powder.

\begin{tabular}{|l|c|}
\hline Element & Weight fraction \\
\hline $\mathrm{SiO} 2$ & 72.5 \\
\hline $\mathrm{Na} 2 \mathrm{O}$ & 13.7 \\
\hline $\mathrm{CaO}$ & 9.8 \\
\hline $\mathrm{MgO}$ & 3.3 \\
\hline $\mathrm{Al} 2 \mathrm{O} 3$ & 0.4 \\
\hline $\mathrm{FeO} / \mathrm{Fe} 2 \mathrm{O} 3$ & 0.2 \\
\hline $\mathrm{K} 2 \mathrm{O}$ & 0.1 \\
\hline
\end{tabular}

The tools and equipment applied through the study is tabulated in Table 2.

Table 2: Tools and equipment applied in the study.

\begin{tabular}{|l|l|l|}
\hline & Manufacturer & \multicolumn{1}{c|}{ Details } \\
\hline Mold & Homemade & Disc and conical, Stainless steel 310 \\
\hline Sieve & Sepahan & Tilor \\
\hline Ball mill & - & - \\
\hline Furnace & Iran Khodsaz & $\begin{array}{l}\text { Model FP6, atmospheric, controlled temperature up } \\
\text { to } 1000^{\circ} \mathrm{C}\end{array}$ \\
\hline Furnace & Azar Koreh & Model TF5/2512505 \\
\hline Flow meter & Arshia & ACA 04 \\
\hline Pressure gauge & - & - \\
\hline Bubble Column & Homemade & - \\
\hline $\begin{array}{l}\text { Recording } \\
\text { Camera }\end{array}$ & SONY & DSC-WX80 \\
\hline
\end{tabular}

Water, ethanol, and kerosene were applied as the liquid. Properties of these liquids are tabulated in Table 3.

Table 3: The properties of polar and non-polar liquids applied in this article.

\begin{tabular}{|l|c|c|c|}
\hline Liquid & $\begin{array}{c}\text { Surface tension } \\
\text { (dync/cm) }\end{array}$ & $\begin{array}{c}\text { Viscosity } \\
\text { (Pa.s) }\end{array}$ & $\begin{array}{c}\text { Density } \\
\left(\mathbf{k g} / \mathbf{~ m}^{\mathbf{3}}\right)\end{array}$ \\
\hline $\begin{array}{l}\text { Distilled } \\
\text { water }\end{array}$ & 73 & 0.0008 & 1000 \\
\hline Ethanol 96\% & 22.3 & 0.001 & 786 \\
\hline Kerosene & $23-32$ & 0.0016 & 820 \\
\hline
\end{tabular}

\subsection{Methods}

Three types of glass bead-copper oxide composite spargers are fabricated: disc sparger manually coated, disc sparger coated with plasma deposition, and conical sparger. 


\subsubsection{Fabrication of Disc Composite Sparger Manually Coated (Sample 1)}

Glass bead powder of $0-63 \mu \mathrm{m}$ size range and copper powder with particle sizes of less than $149 \mu \mathrm{m}$ are utilized. Copper powder passed through sieve 400 mesh is used to manually coat the substrate. The composite sample was heated for 1 hour in an atmospheric furnace at 550 at a rate of $5^{\circ} \mathrm{C} / \mathrm{min}$. Fabrication sequences for this sparger is shown in Fig 1.

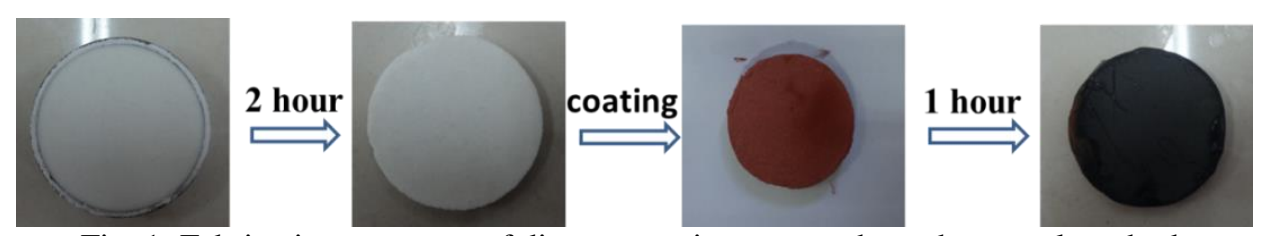

Fig. 1: Fabrication sequence of disc composite sparger through manual method.

\subsubsection{Fabrication of Disc Composite Sparger Through Plasma Focus Deposition (Sample 2)}

For fabricating this substrate, the glass bead powder of $0-63 \mu \mathrm{m}$ size range is ball milled for $420 \mathrm{~min}$. A substrate is fabricated from the resultant powder. A layer of copper with 80 discharges was deposited by applying Mather-type plasma focus deposition device. This device work is based on thermal evaporation [7]. Operation parameters of this device are tabulated in Table 4.

Table 4: Operation parameters of plasma focus deposition.

\begin{tabular}{|l|l|}
\hline Parameter & Value \\
\hline Number of discharge & 80 \\
\hline Capacitor discharge energy $(\mathrm{KJ})$ & 3 \\
\hline Pressure $(\mathrm{mbar})$ & $0.3-1.2$ \\
\hline Voltage $(\mathrm{KV})$ & 21 \\
\hline Target Dimension $(\mathrm{mm})$ & $20 * 10 * 5$ \\
\hline
\end{tabular}

The composite sample was heated for 1 hour in an atmospheric furnace at $550^{\circ} \mathrm{C}$ at the rate of $5{ }^{\circ} \mathrm{C} / \mathrm{min}$. Fabrication sequence of this sparger is shown in Fig. 2.

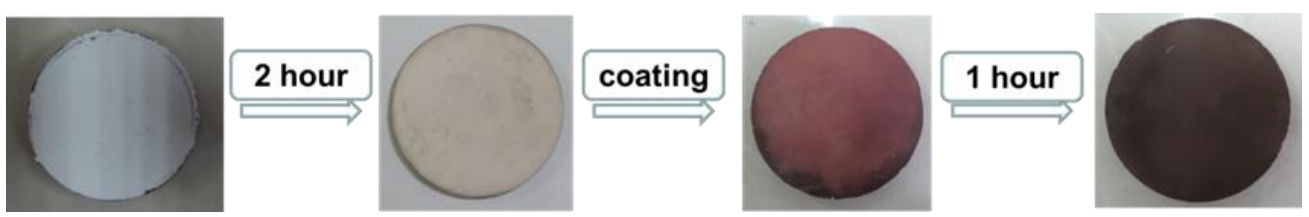

Fig. 2: Fabrication sequence of disc composite sample through plasma focus device.

\subsubsection{Fabrication of Conical Composite Spargers Manually Coated (Sample 3)}

This composite sample was fabricated in $300-700^{\circ} \mathrm{C}$ temperature range. Glass bead powder of $425-600 \mu \mathrm{m}$ size range was utilized to fabricate substrate. Copper powder of $0-20 \mu \mathrm{m}$ size range was then utilized to coat the substrate. Fabrication sequence of this sparger is shown in Fig 3.
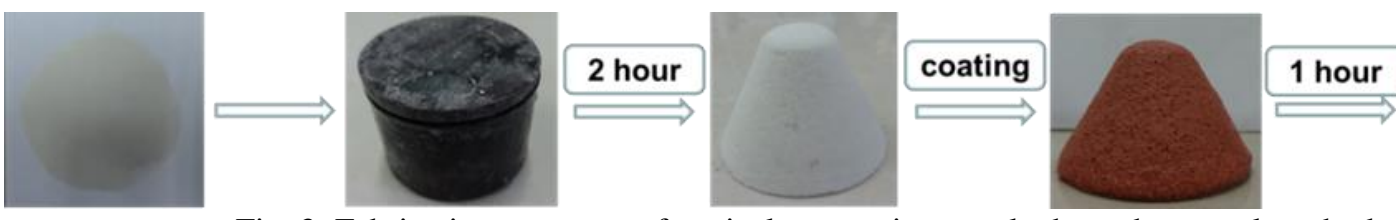

Fig. 3: Fabrication sequence of conical composite sample through manual method.

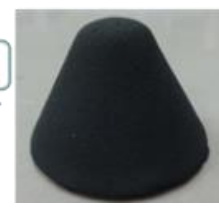


The specifications of the mold for glass conical substrates is shown in Fig. 4.
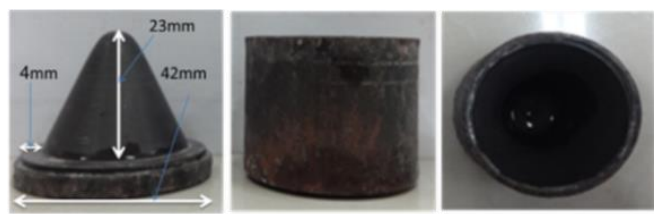

Fig. 4: Conical mold applied to fabricate substrate.

The experimental observations indicate that below $300{ }^{\circ} \mathrm{C}$, sintering does not occur, Fig 5 . Above $700{ }^{\circ} \mathrm{C}$ the pores in the sample are closed.

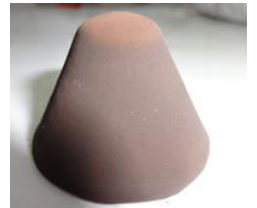

Fig. 5: Fabricated conical composite sample at $300^{\circ} \mathrm{C}$.

\section{Experimental Set-Up}

The experimental setup, to test fabricated spargers, is shown in Fig. 6. Nitrogen gas flows through a flow meter, pressure gauge, sparger, and it leaves the sparger as small bubbles in the bubble column.

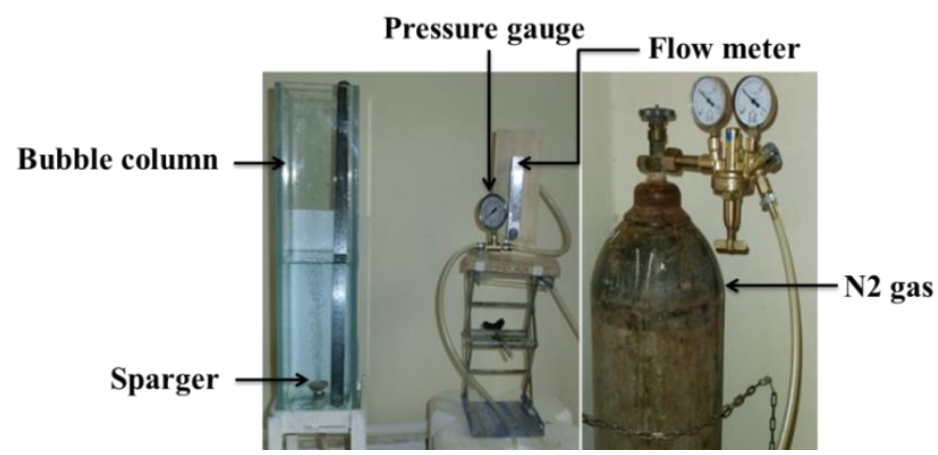

Fig. 6: Bubble column set up to test fabricated spargers.

\section{Results and Discussion}

The produced bubbles of sample 1 in water, ethanol, and kerosene at gas flow rate of $1 \mathrm{~L} / \mathrm{h}$ (litre per hour) are shown in Fig. 7. From water to kerosene the size of bubbles decrease and the number of bubbles increase.

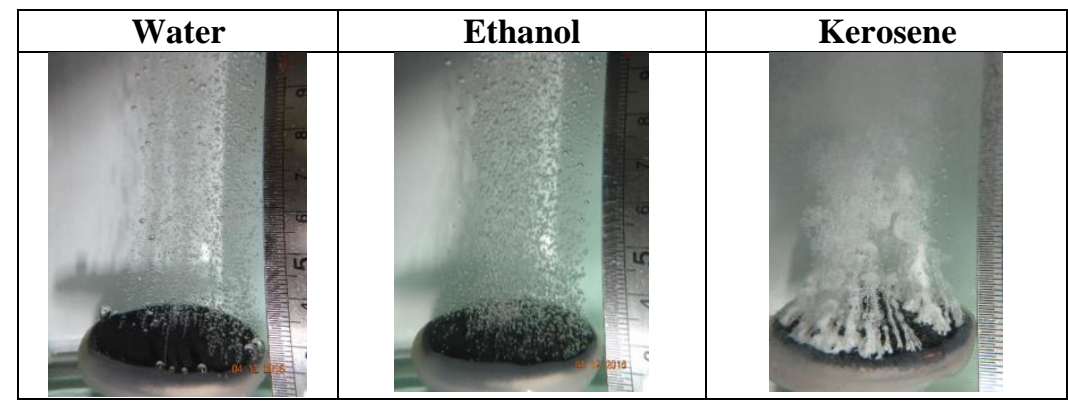

Fig. 7: Produced bubbles for sample 1 in different liquids at $1 \mathrm{~L} / \mathrm{h}$.

The diagram of bubble size distribution is shown in Fig. 8 . 

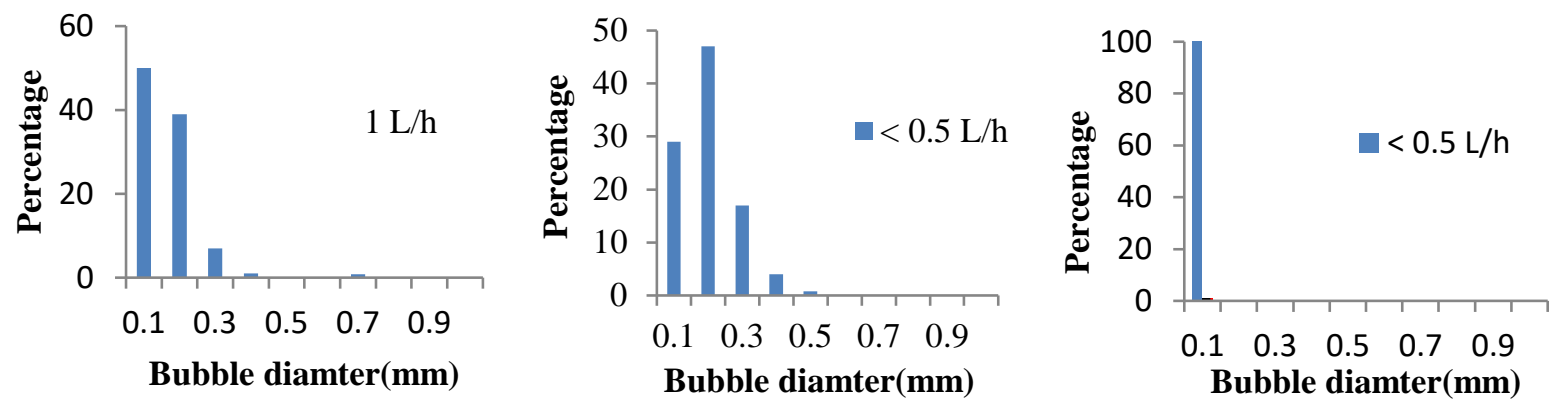

Fig. 8: Bubble size distribution for sample 1 in different liquids and at different gas flow rates.

According to Fig. 8, in water, about $50 \%$ of the bubbles are smaller than $0.1 \mathrm{~mm}$. In ethanol, about $30 \%$ of the bubbles are smaller than $0.1 \mathrm{~mm}$. In Kerosene, $100 \%$ of bubbles are smaller than $0.1 \mathrm{~mm}$. SEM image of sample 1 (a) and its substrate (b) is shown in Fig. 9. Strong connection is created between particles. The figure indicates that through coating of sintered glass bead particles by a layer of copper and sintering in the presence of oxygen, the pore size decreases.
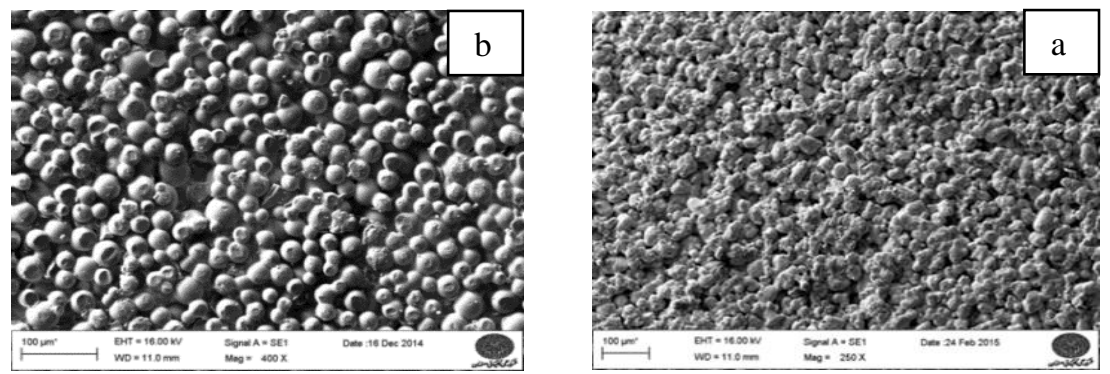

Fig. 9: SEM images of the surface for Sample 1 (a) and its substrate (b).

XRD analysis of sample 1 and its substrate is shown in Fig. 10. This analysis is done to find about the crystalline structure of different samples through fabrication sequences. Crystal phase is not created in raw powder (10-a), nor in glass substrate (10-b), the wide peaks observed indicate that glass substrate and raw powder are amorphous. The peaks related to copper are shown in Fig. 10-c while those for $\mathrm{CuO}$ are shown in Fig. 10-d. Comparison of Figs. 10-c and 10-d indicates that copper is completely converted to $\mathrm{CuO}$. The bond between the copper layer and the glass substrate is chemical, which is due to the presence of oxygen during the sintering process. So oxygen is the binding agent of copper particles.

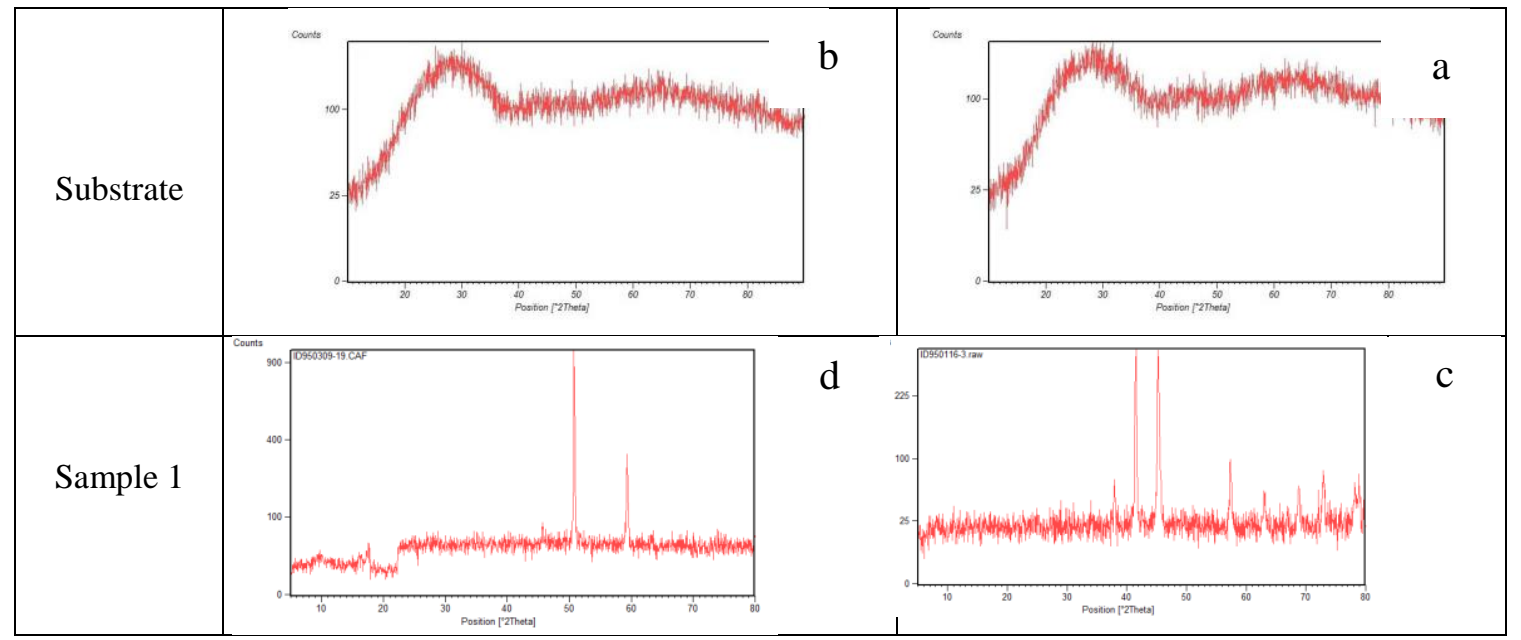

Fig. 10: XRD results of the glass bead powder (a), substrate (b) and copper coated substrate (c) and composite sparger. 
To confirm the role of oxygen, a substrate coated with copper (test sample) was placed inside a tube furnace under nitrogen atmosphere (to prevent oxygen entry) at $5{ }^{\circ} \mathrm{C} / \mathrm{min}$ up to at $500{ }^{\circ} \mathrm{C}$. The results show that, no interconnection between the layer and the substrate is established, and the copper particles do not sintered to substrate. The samples fabricated with and without oxygen are shown in Fig. 11.

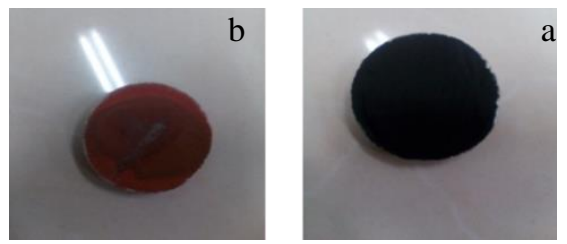

Fig. 11: Fabricated composite samples with (a) and without (b) oxygen.

SEM images of sample 2 and its substrate are shown in Fig. 12. The images represent a uniform distribution of pores and a reduced pore size compared to the SEM images of sample 1.

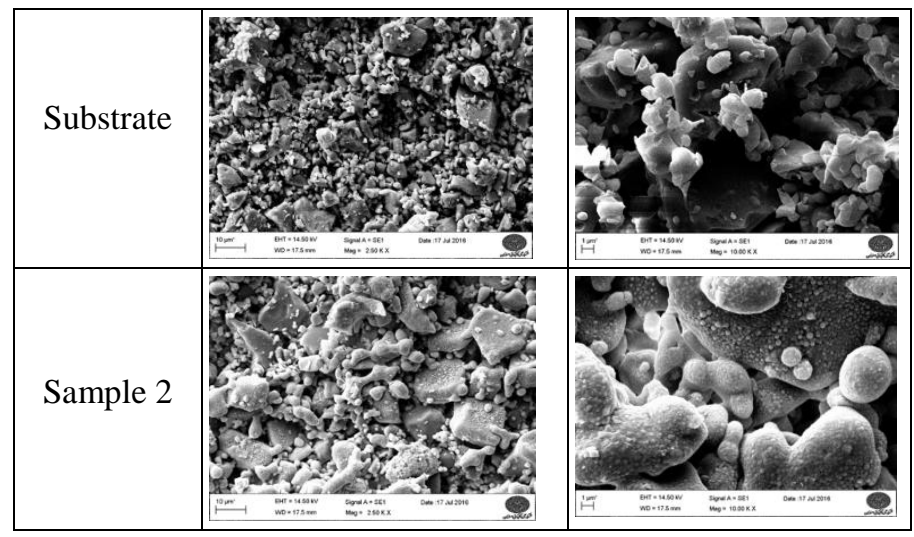

Fig. 12: SEM image for sample 2 and its substrate.

In order to increase the flow rate per unit surface area of injected cross section, conical spargers are fabricated (sample 3). The bubbles produced for sample 3 (fabricated at $600{ }^{\circ} \mathrm{C}$ sintering temperature) in kerosene at $40 \mathrm{~L} / \mathrm{h}$ are shown in Fig. 13. All the bubbles produced by this sample are below $0.1 \mathrm{~mm}$ range. There are some large bubbles at higher distances, too. Analysis of the recoded films indicated that these large bubbles are created by collision of smaller bubbles.

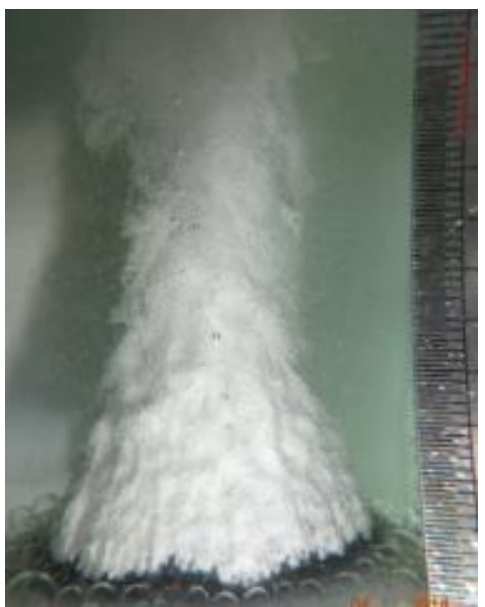

Fig. 13: Image of produced bubbles for sample 3 in kerosene at $40 \mathrm{LPH}$. 


\section{Conclusion}

By controlling the sintering parameters through this reaction and sintering method $100 \%$ bubbles of less than $0.1 \mathrm{~mm}$ diameter is fabricated. In kerosene a cloudy bubble column is formed above the sparger and gas flow rates up to 10 $\mathrm{L} / \mathrm{h} / \mathrm{cm}^{2}$, with low pressure drops, is reached. These results open horizons for the application of the new spargers in polar and non-polar liquids and studying bubble columns with much smaller bubbles than those reported in the literature, so far. Consequently, more efficient bubble columns and higher efficiencies of mass transfer are expected in the field of practice.

\section{Acknowledgement}

The support of Dr. Babak Shirani and Milad Miremad in the coating experiments and applying their homemade Mather Plasma Focus device is acknowledged. The authors thank the financial support of the dean of research at the University of Isfahan.

\section{References}

[1] R. H. Todd, D. K. Allen, L. Alting, "Manufacturing Processes Reference Guide,” Industrial Press., 1994.

[2] Höganäs AB laboratory, sintering "Höganäs Handbook for sintered components," 1st ed, Höganäs AB, Sweden, pp. 67-117, 2013.

[3] H. N. Ch'ng, J. Pan, "Sintering of particles of different sizes," Acta Mater., vol. 55, pp. 813-824, 2007.

[4] B. M. Goortani, F. Gitzhofer, Method of production of solid and porous films from particulate materials by high heat flux source, WIPO PCT Patent: WO 2009/027764, 2009.

[5] P. Snabre, F. I. Magnifotcham, "Formation and rise of a bubble stream in a viscous liquid," vol. 377, pp. 369-377, 1998.

[6] B. Mostajeran Goortani, R. Izadi, M. Keramat, "Fabrication and characterization of low cost silica spargers: Toward Smaller Bubbles," Advanced Powder Technology, vol. 28, no. 3, pp. 910-921, 2017.

[7] M. Ohering, "Materials Science of Thin Films, Deposition and Structure," 2nd ed, New York, Academic Press, 2002. 